\title{
AMENDMENTS
}

\section{Author Correction: Formation of metre-scale bladed roughness on Europa's surface by ablation of ice}

Daniel E. J. Hobley iD, Jeffrey M. Moore, Alan D. Howard and Orkan M. Umurhan

Correction to: Nature Geoscience https://doi.org/10.1038/s41561-018-0235-0, published online 8 October 2018.

In the version of this Article originally published, in Fig. 3a the peak values of $M$ in the northern and southern mid-latitudes in one hemisphere were incorrect. In addition, the two hemispheres were labelled incorrectly. The hemispheres should have been as shown below. This has now been corrected.
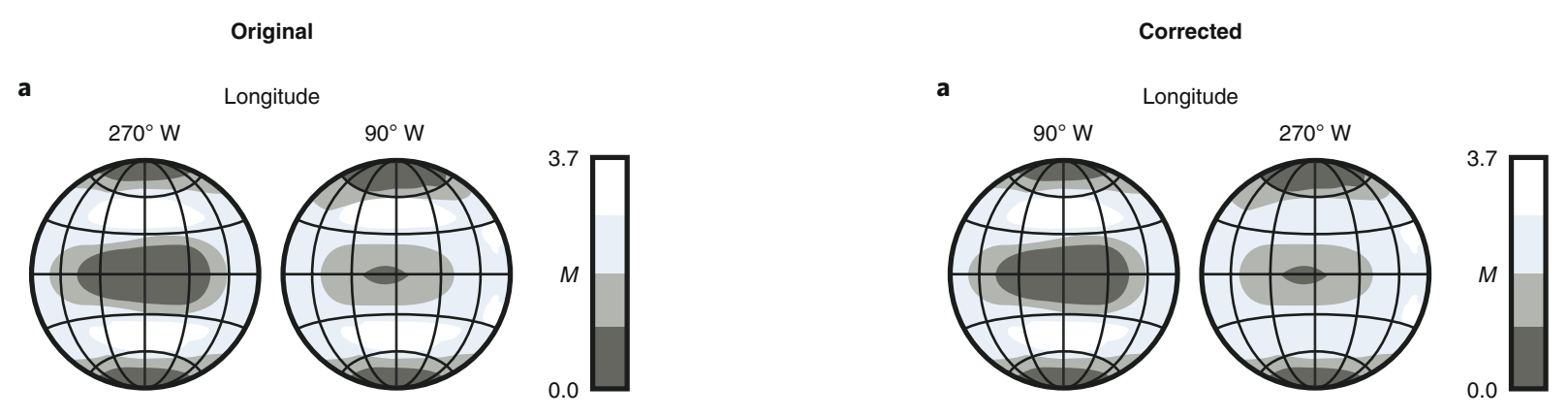

Fig. 3 | Original and corrected.

Published online: 13 November 2019

https://doi.org/10.1038/s41561-019-0501-9

() The Author(s), under exclusive licence to Springer Nature Limited 2019

\section{Author Correction: Reply to: Validity of managing peatlands with fire}

R. H. Marrs (D), E.-L Marsland, R. Lingard, P. G. Appleby, G. T. Piliposyan, R. J. Rose, J. O’Reilly, G. Milligan (D, K. A. Allen,

J. G. Alday (D), V. Santana, H. Lee $\mathbb{D}$, K. Halsall and R. C. Chiverrell $\mathbb{D}$

Correction to: Nature Geoscience https://doi.org/10.1038/s41561-019-0478-4, published online 28 October 2019.

In the version of this Matters Arising originally published, in the third from last sentence of the last paragraph, the word 'not' was mistakenly omitted; the sentence should have read: 'Therefore, although we do not advocate prescribed burning everywhere, we merely suggest that it be considered as a tool in our armoury to mitigate wildfire impacts, and hence our research is timely. This has now been corrected.

Published online: 20 November 2019

https://doi.org/10.1038/s41561-019-0508-2

(C) The Author(s), under exclusive licence to Springer Nature Limited 2019 